\title{
Nutrition, Vitamin A
}

National Cancer Institute

\section{Source}

National Cancer Institute. Nutrition, Vitamin A. NCI Thesaurus. Code C16015.

Role of Vitamin A, its precursons, and its analogs in cancer causation or prevention and in general health. 